\title{
“Curriculum swaps" as a pathway into a geographically-distributed instructional community
}

\author{
Alice Olmstead ${ }^{1}$ and Chandra Turpen ${ }^{2}$ \\ ${ }^{1}$ Texas State University, Department of Physics, San Marcos, TX 78666 \\ ${ }^{2}$ University of Maryland, Department of Physics, College Park, MD 20742
}

\begin{abstract}
We are designing and testing ways to build and sustain geographically-distributed, topic-specific instructional communities. Our work centers on the Living Physics Portal, a virtual space for introductory physics for life sciences (IPLS) instructors. Here, we show initial evidence that a series of facilitated, synchronous "curriculum swaps" can help newcomers to see themselves as more central participants in an instructional community and may lead to higher levels of future engagement.
\end{abstract}

\section{INTRODUCTION}

Discipline-based education researchers and change leaders often aim to promote use of the same instructional materials across many classrooms. While sharing materials, particularly highly innovative ones, could accelerate positive change, the simplest approaches to doing this have limited effectiveness [1]. For example, many authors who hope to see their own materials used broadly often only make their materials available online and advertise them [1]. Passive dissemination approaches like this are largely unsuccessful [1].

Prior research has generated recommendations about how change leaders can more effectively pursue collective instructional improvement. For example, research shows that instructors are more likely to pursue instructional changes if they have: opportunities to learn about the pedagogical logic behind others' instructional materials [2, 3], support for experimentation and adaptation [2, 4], connections with people who can help them when they encounter implementation challenges [3], and genuine invitations to act as partners in the change process [4].

Change leaders have started to explore how virtual spaces could align with these recommendations. There is a growing recognition of the affordances of virtual spaces that combine digital curricular libraries with community support [57]. Such combinations could avoid the pitfalls of digital libraries alone. Because this is a relatively new trend, we have limited understanding of what specific design elements are effective in this arena.

We are exploring the problem of designing virtual instructional communities through the Living Physics Portal (livingphysicsportal.org). Instructors of introductory physics for life sciences (IPLS) courses currently struggle to access appropriate resources, even though many curriculum development projects have been supported by NSF [8]. This paper describes the design of community organizational structures and activities around the Portal. We present initial evidence of faculty outcomes from a pilot community activity.

\section{LITERATURE REVIEW}

Scholars have articulated important differences between social networks and online communities: networks focus on building one-to-one relationships between users and support sharing between users, whereas online communities cultivate a sense of shared purpose and support cooperation and collective action [9]. Researchers who have studied the growth of online communities have identified markers of thriving communities that can guide new or struggling communities as they aspire to build up their membership.

In this paper, we use Howard's conceptualization of what makes a thriving online community [9]. He articulates four desirable qualities of community members' experiences: remuneration (am I getting something valuable out of participating); influence (do I have a say in shaping the community); belonging (do I fit in the community); and significance (is the community prestigious). These four qualities are based on broader literature about communities (such as Wenger's communities of practice [10]) and empirical evidence of how various virtual communities succeed and fail.

Strategies for cultivating community include developing routines that are meaningful to community members, highlighting goals that are shared among members, and building the capacity of newcomers to engage in the important activities of central members [9,11]. Some scholars have conceptualized short-lived working groups as potential precursors to collaborative teamwork and communities of practice [12]. Working groups are comprised of people who often act independently but perform similar or complementary tasks centered on common goals, norms, and purposes [12]. Groups tend to work best when they plan to dissolve after a short time ( $\sim 3$ months or less) [9] and have well-defined tasks [9, 12].

One intended shared purpose of many instructional communities is to support the pedagogical growth of its members. To do so, communities must develop a suite of routines and practices that are generative for refining thinking about teaching and learning. Literature about teacher professional development can give us insights into what these practices should look like. For example, Horn argues that discussions centered on concrete artifacts of classroom practice (e.g., materials and specific recalled experiences) can lead to pedagogical learning [13]. Horn also argues that teachers should strive to generate realistic hypotheses about how variations in instructional choices might influence students' engagement [13]. They find that less experienced teachers often struggle to do so, and facilitation is likely needed to create opportunities to learn [13]. These principles for cultivating pedagogical growth influenced how we designed community activities for the Portal. 


\section{METHODS}

\section{A. Design of study setting}

Our team designed a variety of community activities for the Living Physics Portal. We prioritize activities that might support all community members, including newcomers, in becoming more central to the Portal community and learning to become more effective instructors. Here, we focus on one such activity that we call "curriculum swaps." Our curriculum swaps are a series of virtual, synchronous conversations centered on participants' own curricular materials.

We aimed to form groups in ways that minimized power differentials (e.g., grouping together people who have similar clout within the Portal community) and gave people exposure to a variety of perspectives (e.g., grouping biophysicists with other physicists). We created a list of instructors who expressed enthusiasm during site usability testing and/or had downloaded materials from the Univ. of Maryland's NEXUS/Physics curriculum repository in the past 5 years. We predicted that this list included community newcomers who would be likely to participate. We contacted 21 people who represented a range of institution types and biophysics expertise. We successfully recruited the first 5 respondents to participate in a group. 4 of 5 participants had created IPLS materials previously and shared their materials at a meeting. We also tested curriculum swaps with two groups of people who were closely connected to the Portal project team.

Before the curriculum swap meetings, we sent participants guiding questions that encouraged them to reflect on the logic behind the design of their curricular materials and how past use of these materials had played out in their classrooms. During each meeting, participants took turns sharing a piece of curriculum that they had created and implemented in their classrooms. A facilitator (the second author) encouraged the sharer to address the guiding questions. The facilitator also encouraged other participants to ask questions and provide feedback. Participants were invited to give feedback on the curriculum swap activity and the overall Portal design.

\section{B. Analytical approach}

We designed the curriculum swaps such that they might support shifts in becoming more central members of the Portal community and learning about pedagogy. But these shifts will not necessarily be coupled: it could be possible to have positive outcomes in one dimension but not the other. We video recorded each virtual curriculum swap meeting such that we can pursue qualitative analysis. For this short analysis, we choose to focus on only the extent to which curriculum swaps have the potential draw people into a virtual instructional community. With this goal in mind, we deliberately focus on only the sessions with the group of newcomers.

We take this analytical focus for several reasons. First, in our initial pass through the data, we noticed evidence of the newcomers experiencing a sense of community that we wanted to unpack. Whether or not curriculum swaps can support more central participation of newcomers is a strong indicator of whether such activities can help the community to grow. We wanted to know whether and how this apparently new sense of community might have been derived from their participation in the curriculum swap.

We pursue qualitative analysis of participants' talk during virtual meetings driven by the research question: Can virtual "curriculum swaps" effectively draw newcomers into a geographically-distributed, topic-specific instructional community? We operationalize this by focusing on participants' experiences of remuneration, influence, belonging, and/or significance [9] within the Portal community (see Table II). We coded transcripts of these virtual curriculum swap meetings for evidence of these qualities. We show representative quotes from the 5 participants (pseudonyms: Elijah, Isabella, Logan, Olivia, and William).

\section{ANALYSIS}

\section{A. Remuneration}

In the curriculum swap discussion, the facilitator asks the participants what motivates them to want to share their materials through the Portal. In their responses, we see evidence that instructors can envision getting something out of participating in the Portal community. Participants make several prospective statements about what they anticipate they would gain from this future community-related action. Their reasons include "fame and fortune" when other people use their materials, the ability to show evidence of their contributions for broader impacts and/or promotion documents, and the potential to get feedback from like-minded colleagues. Logan elaborates on this last idea:

Just knowing that there's a community that is going to be having these conversations, that's going to be sharing their ideas, it makes me want to share my ideas so that there's this equal sharing, but that I'm inspired to share and I'm willing to listen and get feedback in maybe even more critical ways than I might normally because it's a group that cares so much about this. It's not getting critical feedback from, it's like, 'Well, I think you're trying something too new and you should stay more standard.' That's not the feedback I want. It's like, 'Wow, that's awesome. You tried that. Here's a quick few things I see aren't working. Here's how you could make it better to do this awesome thing that you're doing,' and that makes me want to share.

Because these optimistic projections about the value of participating in the Portal community come after participants had shared with each other within the curriculum swap, we suspect that the curriculum swap activity positively influenced 
TABLE I. Four perceptions that central members of a thriving community experience: remuneration, influence, belonging, and significance (RIBS) [9], along with summaries of evidence that shows curriculum swap participants experienced each of these or might in the future.

\begin{tabular}{lll}
\hline \hline Perception & Definition & Examples of evidence in data \\
\hline Remuneration & Benefits from participating in the community & $\begin{array}{l}\text { Participants perceive that high quality materials are available; } \\
\text { Participants report a sense of obligation to give back to the community } \\
\text { Influence }\end{array}$ \\
Ability to shape community activities & $\begin{array}{l}\text { Participants learn that others might use their materials; participants } \\
\text { make suggestions for Portal features and community activities }\end{array}$ \\
Belonging & $\begin{array}{l}\text { Fit within the community (co-constructed } \\
\text { with others) }\end{array}$ & $\begin{array}{l}\text { Participants use collective language to describe themselves within the } \\
\text { community; Participants articulate a shared community purpose }\end{array}$ \\
Significance & Importance of the community to outsiders & $\begin{array}{l}\text { Participants see the Portal community as potentially able to help other } \\
\text { instructors connect biology and physics }\end{array}$ \\
\hline \hline
\end{tabular}

their perspectives. Elijah explicitly makes this link when describing his motivations to participate as "selfish." He says:

I've already been able to learn about some outstanding things like what Logan did with the circulatory system and what Isabella did today, so I figure if I'm going to be allowed to stay in this community, I should post some things too.

Elijah's sense of obligation to give back to the community provides strong evidence that he feels remuneration.

\section{B. Influence}

Participants sometimes describe how they might adopt or adapt each others' materials for their own use. They tend to praise the materials in the process. Such statements seem likely to provide participants with a sense of influence in a localized sense. For example, Logan praises Isabella's materials by saying:

I thought this problem was really cool. I've actually been looking a lot into case studies lately. I have a couple of collaborators that I'm working with to put together a grant proposal to do some case studies... and I'm reading this setup and I'm thinking, 'This will be perfect for one of the longer case studies.'

This suggests to Isabella that her work will shape another community member's instruction, as well as potentially their colleagues' local work.

Participants also make bids to shape community activities at a larger scale. Some of these bids are very broad and diffuse, such as their opinions on the instructional goals they would like to see the community take up. Other bids are more specific and concrete. For example, Olivia suggests that the Portal could house video lectures about IPLS topics:

Little 15-minute lectures, I mean that's something that the IPLS effort that Chandra's leading, if we made up video lectures, maybe that would be something that could be included.
Suggestions for Portal features like these are common in the curriculum swaps. They are often prompted by the facilitator, but sometimes come up more organically (as above). Voicing suggestions to Portal leaders may be a precursor to feeling a sense of influence in the broader community, and a sign that participants felt the potential to influence the community. However, the long-term impact on sense of influence is likely contingent on whether or not participants see their suggestions taken up.

\section{Belonging}

We see evidence that participants begin to experience a sense of belonging in their curriculum swap group, and potentially the broader Portal community. This evidence appears repeatedly in the collective language participants use to position themselves. Participants explicitly use the word "we" to describe the curriculum swap group and/or the Portal community. They also explicitly talk about "community" in both of these contexts. For example, Elijah says:

Those [shared materials] are very helpful because it helps me think of how I might adapt it to my class. So the examples we've gone through here in our little community have provided that information for me. It helps a great deal in deciding whether or not I would like to use that, and then finally how could I use it?

Because these instructors had not (to our knowledge) met each other previously, we see this as strong evidence that participating in the curriculum swap increased their sense of belonging at least within their small group.

Moreover, participants sometimes articulate a shared purpose for the broader Portal community, again positioning themselves as members within it. For example, Olivia says:

This IPLS website is really supposed to be not just watered down physics for life science students, but really teaching life science and so I think there has to be a stronger emphasis on the topics and the curriculum [relative to PhysPort]. 
...if we want to put biology into the physics, we have to have a place where that's really front and center.

As we noted in \$I participants' ability to see a common purpose among community members is closely connected to their perception that a community exists at all. Thus, statements about what the community is all about enable participants to feel that they are part of it.

\section{Significance}

We find some evidence that participants see the Portal community as having the potential to be significant to community outsiders. Specifically, they imagine the Portal community as having the capacity to influence the instruction of colleagues who have not participated and may struggle to integrate biology and physics. For example, Logan suggests, "So this is where we need to somehow all be able to help each other through this portal to be able to almost help teach some of the biology to our colleagues." Olivia suggests that she, and people like her, could identify relevant physics in the biological examples, "There should be an onus on people like me and Isabella to make sure that we can explain where the physics is for people who are looking for it." We note that this sense of significance is forward-looking rather than current, i.e., participants suggest that the community could have significance in the future. These data do suggest that participants could experience a growing sense of significance over time, if their ideas about helping their colleagues plays out successfully.

\section{DISCUSSION \& CONCLUSION}

Our analysis shows that virtual curriculum swaps can help to grow instructional communities. Specifically, we show that curriculum swaps among community newcomers can increase participants' perceptions of remuneration, influence, belonging, and significance for an instructional community. Based on existing literature, we suspect that both the open invitations to contribute to community decisions [9] and the opportunity to engage in a central community practice together (reflecting on instructional materials and classroom implementation) [13] helped to generate the outcomes we observe.

Our data also supports the idea that while group activities may ultimately lead to the development of a strong community [12], this is not guaranteed. Perhaps unsurprisingly, we see stronger evidence that participants experienced a sense of community within their small group than within the Portal community as a whole. In order for newcomers perceptions' of remuneration, influence, belonging, and significance within the Portal community to solidify, they likely need to engage in additional community activities. Our data so far suggests that participants at least aspire to do so. Future research could track the behaviors of past curriculum swap participants to explore this issue further.

Lastly, as mentioned earlier, we do not analyze for pedagogical learning in this paper. Given the current landscape of undergraduate instruction, supports for pedagogical learning are important if we are to significantly improve teaching and learning in IPLS courses through the Portal. Moreover, given the typical values and pedagogical expertise of most central instructional community members, it is likely necessary for newcomers to make pedagogical gains in order to become truly central within the Portal community. Future research could explore the extent to which pedagogical growth is enabled by curriculum swaps or other activities.

Like many disciplinary instructional change projects, the ultimate goal of the Living Physics Portal project is to improve instruction in a topical area. A thriving community of instructors that contribute to and draw from a library of relevant curricular materials is important for advancing this goal. Here, we show that virtual curriculum swaps can serve as one mechanism for expanding a topic-specific instructional community. We advocate for continued design and experimentation focused on building and sustaining such communities.

\section{ACKNOWLEDGMENTS}

This work is supported by NSF-DUE 1624478. The authors thank Edward F. Redish, Sarah (Sam) McKagan, Adrian Madsen, Remy Dou, and the rest of the Living Physics Portal project team.
[1] C. Stanford et al., J. Sci. Educ. Tech. 26(4), 418-437 (2017).

[2] C. Turpen, M. Dancy, \& C. Henderson, Phys. Rev. Phys. Educ. Res. 1210116 (2016).

[3] M. Dancy, C. Henderson, \& C. Turpen, Phys. Rev. Phys. Educ. Res. 12(1) 10110 (2016).

[4] C. Henderson \& M. H. Dancy, Am. J. Phys. 76(1), 79 (2008).

[5] A. Kezar \& S. Gehrke, Pullias Center for Higher Education Report, 2015.

[6] P. Irving \& M. Caballero, Phys. Educ. Res. Conf. Proc. (2017).

[7] K. Kasten \& C. Manduca, Change, 49(6), 14-22 (2017).

[8] Amer. Assoc. of Phys. Teachers, Conference on Introductory Physics for Life Sciences Report, (2015).
[9] T. Howard, Design to thrive: Creating social networks and online communities that last (Morgan Kaufmann, 2009).

[10] E. Wenger, Communities of practice: Learning, meaning, and identity (Cambridge University Press, 1999).

[11] J. R. Katzenbach \& D. K. Smith, Harv. Bus. Rev., 71(2), 111120 (1993).

[12] A. Gilley \& S. J. Kerno, Adv. in Dev. Hum. Resour., 12(1), 46-60 (2010).

[13] I. S. Horn \& B. D. Kane, J. Learn. Sci.,24(3), 373-418 (2015). 